\title{
Survival and Complication Rates of Metastasectomy in Patients With Metastatic Renal Cell Carcinoma Treated Exclusively With Targeted Therapy: A Combined Population-based Analysis
}

\author{
CARLOTTA PALUMBO ${ }^{1,2^{*}}$, ANGELA PECORARO ${ }^{1,3 *}$, SOPHIE KNIPPER ${ }^{1,4}$, GIUSEPPE ROSIELLO $^{1,5}$, \\ ZHE TIAN $^{1}$, SHAHROKH F. SHARIAT ${ }^{6,7,8,9,10}$, CLAUDIO SIMEONE ${ }^{2}$, ALBERTO BRIGANTI $^{5}$, \\ FRED SAAD $^{1,11}$, ALFREDO BERRUTI ${ }^{12}$, ALESSANDRO ANTONELLI $^{2}$ and PIERRE I. KARAKIEWICZ ${ }^{1,7}$ \\ ${ }^{1}$ Cancer Prognostics and Health Outcomes Unit, University of Montreal Health Center, Montreal, QC, Canada; \\ ${ }^{2}$ Urology Unit, ASST Spedali Civili of Brescia, Department of Medical and Surgical Specialties, \\ Radiological Science and Public Health, University of Brescia, Brescia, Italy; \\ ${ }^{3}$ Department of Urology, San Luigi Gonzaga Hospital, University of Turin, Orbassano, Italy; \\ ${ }^{4}$ Martini Klinik, University Medical Center Hamburg-Eppendorf, Hamburg, Germany; \\ ${ }^{5}$ Division of Experimental Oncology/Unit of Urology, Urological Research Institute (URI), \\ IRCCS San Raffaele Scientific Institute, Milan, Italy; \\ ${ }^{6}$ Department of Urology, Comprehensive Cancer Center, Medical University of Vienna, Vienna, Austria; \\ ${ }^{7}$ Department of Urology, Weill Cornell Medical College, New York, NY, U.S.A.; \\ ${ }^{8}$ Department of Urology, University of Texas Southwestern, Dallas, TX, U.S.A.; \\ ${ }^{9}$ Department of Urology, Second Faculty of Medicine, Charles University, Prague, Czech Republic; \\ ${ }^{10}$ Institute for Urology and Reproductive Health, \\ I.M. Sechenov First Moscow State Medical University, Moscow, Russia; \\ ${ }^{11}$ Department of Urology, University of Montreal Hospital Center (CHUM), Montreal, QC, Canada; \\ ${ }^{12}$ Medical Oncology Unit, ASST Spedali Civili of Brescia, Department of Medical and Surgical Specialties, \\ Radiological Science and Public Health, University of Brescia, Brescia, Italy
}

\begin{abstract}
Aim: This study analyzed the effect of metastasectomy on overall mortality (OM) and perioperative outcomes in patients with metastatic renal cell carcinoma ( $m R C C)$ treated exclusively with targeted therapy. Materials and Methods: Using the Surveillance, Epidemiology, and End Results (SEER) database (2006-2015), Kaplan-Meier analyses and multivariable Cox regression models tested for OM. Using the National Inpatient Sample (NIS) database (2006-2015), complication rates and in-hospital mortality were evaluated. Results: Within the SEER database, 437
\end{abstract}

\footnotetext{
*These Authors contributed equally to this work.

Correspondence to: Carlotta Palumbo, MD, Urology Unit, ASST Spedali Civili of Brescia, Department of Medical and Surgical Specialties, Radiological Science and Public Health, University of Brescia, Piazzale Spedali Civili 1, 25123, Brescia, Italy. Tel: +39 3491289501, Fax: +390303995055, e-mail: palumbo.carlotta@ gmail.com
}

Key Words: Renal cell carcinoma, metastasectomy, metastasis, survival, complication.
(12.2\%) out of 3,654 patients underwent metastasectomy. Metastasectomy was associated with lower OM risk (median survival 11 vs. 9 months, hazard ratio=0.83; $p=0.002)$. Within the NIS database, 351 such patients were identified. Complications and in-hospital mortality were $55.0 \%$ and $4.6 \%$, respectively. Conclusion: Metastasectomy in patients with mRCC treated exclusively with targeted therapy is associated with lower OM risk, however, based on short duration of expected survival. Complications and in-hospital mortality rates are not negligible.

Both European and North-American guidelines (1, 2) consider metastasectomy a treatment option in metastatic renal cell carcinoma ( $\mathrm{mRCC}$ ). However, data supporting the role of metastasectomy in the targeted therapy era in patients with mRCC treated with cytoreductive nephrectomy are scarce $(3,4)$.

To the best of our knowledge, no previous studies have examined the role of metastasectomy in a controlled fashion, using a formal control group that was not treated with metastasectomy, in mRCC treated exclusively with targeted therapy. Therefore, we assessed the effect of metastasectomy 
Table I. Descriptive characteristics of 3,654 patients with metastatic renal cell carcinoma (RCC) treated exclusively with targeted therapy, according to additional metastasectomy status, identified within the Surveillance, Epidemiology, and End Results (SEER) database (2006-2015).

\begin{tabular}{|c|c|c|c|c|}
\hline Variable & & $\begin{array}{l}\text { Metastasectomy } \\
(\mathrm{n}=437,12.0 \%)\end{array}$ & $\begin{array}{l}\text { No metastasectomy } \\
(\mathrm{n}=3,217,88.0 \%)\end{array}$ & $p$-Value \\
\hline Age at diagnosis, years & Median (IQR) & $62(54-69)$ & $64(56-72)$ & $<0.001$ \\
\hline \multirow{3}{*}{ Ethnicity, n (\%) } & Caucasian & $363(83.1)$ & $2645(82.2)$ & 0.5 \\
\hline & African American & $38(8.7)$ & $335(10.4)$ & \\
\hline & Other & $36(8.2)$ & $237(7.4)$ & \\
\hline \multirow[t]{2}{*}{ Gender, n (\%) } & Male & $308(70.5)$ & $2250(69.9)$ & 0.8 \\
\hline & Female & $129(29.5)$ & $967(30.1)$ & \\
\hline \multirow[t]{4}{*}{ Marital status, n (\%) } & Married & $272(62.2)$ & $1940(60.3)$ & 0.9 \\
\hline & Never married & $66(15.1)$ & $509(15.8)$ & \\
\hline & Previously married & $86(19.7)$ & $664(20.6)$ & \\
\hline & Unknown & $13(3.0)$ & $104(3.2)$ & \\
\hline \multirow[t]{2}{*}{ Year of diagnosis, n (\%) } & $2006-2010$ & $183(41.9)$ & $1258(39.1)$ & 0.3 \\
\hline & 2011-2015 & $254(58.1)$ & $1959(60.9)$ & \\
\hline \multirow[t]{2}{*}{ Socioeconomic status, $\mathrm{n}(\%)^{\#}$} & Quartile 1 & $112(25.6)$ & $826(25.7)$ & 0.9 \\
\hline & Quartile 2-4 & $325(74.4)$ & $2391(74.3)$ & \\
\hline \multirow[t]{3}{*}{ Population density, n (\%) } & Urban & $378(86.5)$ & $2785(86.6)$ & 0.9 \\
\hline & Rural & $58(13.3)$ & $424(13.2)$ & \\
\hline & Unknown & $1(0.2)$ & $8(0.2)$ & \\
\hline \multirow[t]{4}{*}{ SEER region, $\mathrm{n}(\%)$} & West & $224(51.3)$ & $1627(50.6)$ & 0.7 \\
\hline & Midwest & $57(13.0)$ & 367 (11.4) & \\
\hline & North-East & $52(11.9)$ & $407(12.7)$ & \\
\hline & South & $104(23.8)$ & $816(25.4)$ & \\
\hline \multirow[t]{5}{*}{ T-Stage, n (\%)* } & $\mathrm{T} 1$ & $103(23.6)$ & $607(18.9)$ & 0.001 \\
\hline & $\mathrm{T} 2$ & $84(19.2)$ & $600(18.7)$ & \\
\hline & T3 & $61(14.0)$ & $659(20.5)$ & \\
\hline & $\mathrm{T} 4$ & $52(11.9)$ & $487(15.1)$ & \\
\hline & $\mathrm{Tx} / 0$ & $137(31.4)$ & $864(26.9)$ & \\
\hline \multirow[t]{2}{*}{ N-Stage, n (\%)* } & $\mathrm{N} 0 / \mathrm{NX}$ & $312(71.4)$ & $2068(64.3)$ & 0.004 \\
\hline & $\mathrm{N} 1$ & $125(28.6)$ & $1149(35.7)$ & \\
\hline \multirow[t]{3}{*}{ Histology, n (\%) } & $\mathrm{ccRCC}$ & $205(46.9)$ & $1258(39.1)$ & 0.006 \\
\hline & Non-ccRCC & $44(10.1)$ & $342(10.6)$ & \\
\hline & NOSRCC & $188(43.0)$ & $1617(50.3)$ & \\
\hline \multirow[t]{3}{*}{ Fuhrman grade, n (\%) } & $\mathrm{G} 1 / \mathrm{G} 2$ & $11(2.5)$ & $322(10.0)$ & $<0.001$ \\
\hline & G3/G4 & $36(8.2)$ & $470(14.6)$ & \\
\hline & Unknown & $390(89.2)$ & $2425(75.4)$ & \\
\hline
\end{tabular}

IQR: Interquartile range; ccRCC: clear-cell renal cell carcinoma; NOS: not otherwise specified. *7th TNM (7). \#Defined according to census tractlevel socioeconomic status (SES) index provided by the SEER database.

on overall mortality (OM) in a large cohort identified within the Surveillance, Epidemiology, and End Results (SEER) database (2006-2015). Moreover, we also relied on the National Inpatient Sample (NIS) database to examine complication rates and in-hospital mortality following metastasectomy.

\section{Materials and Methods}

Within the SEER database (2006-2015) (5), our study focused on patients aged 18 years or older with primary diagnosis of mRCC [International Classification of Disease for Oncology (ICD-O) site codes C64.9] (6). Patients treated exclusively with targeted therapy and those with known information on metastasectomy status were included. Autopsy and death certificate cases were excluded.
Covariates included age, gender, ethnicity, marital status, socioeconomic status, residence area, SEER-registry region, 2017 TNM classification (7), Fuhrman grade and histological subtypes. Descriptive statistics compared metastasectomy with no metastasectomy. Subsequently, estimated annual percentage change (EAPC) tested for annual metastasectomy rate. Multivariable logistic regression models predicting metastasectomy were also fitted. Adjustment variables consisted of all available covariates. KaplanMeier analyses and multivariable Cox regression (MCR) models tested for $\mathrm{OM}$ according to metastasectomy or not. Adjustment variables consisted of all available covariates. Finally, survival analyses were repeated after 1: 4 propensity score matching (PSM). The two groups were balanced according to all available covariates.

Within the NIS database (2006-2015) (8), we focused on patients aged 18 years or older with primary diagnosis of mRCC (ICD-9 codes 189.0, 197.x, 198.x). Patients treated with metastasectomy were 

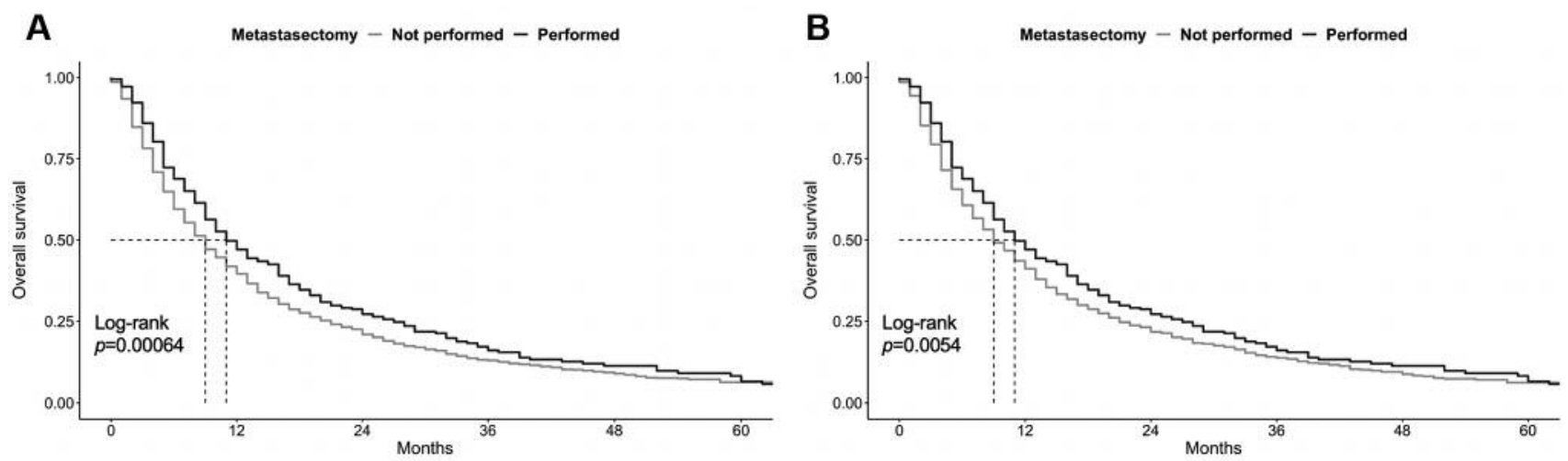

Figure 1. Kaplan-Meier curves for patients with metastatic renal cell carcinoma treated exclusively with targeted therapy identified within the Surveillance, Epidemiology and End Results database between 2006 and 2015, before (A) and after (B) 1:4 propensity score-matching, depicting overall survival rates stratified according to metastasectomy (performed, $n=3,217$; not performed $=437$ ).

identified using concomitant codes of the site of metastases, as well as the code for the procedure corresponding to organ-specific resection, as previously described (9). Patients treated with both metastasectomy and nephrectomy (ICD-9 codes 55.4, 55.51, 55.52, 55.54) were excluded. Descriptive statistics focused on metastasectomy rates, as well as complication rates and in-hospital mortality. Subsequently, separate univariable logistic regression models assessed the association between covariates and overall complications. All results were weighted to reflect national estimates.

All statistical tests were two-sided with a level of significance set at $p<0.05$ and performed using the $\mathrm{R}$ software environment for statistical computing and graphics (version 3.4.1; http: //www.rproject. org/).

\section{Results}

Within the SEER database (2006-2015), 3,654 patients with mRCC were identified, of whom 437 (12.2\%) underwent metastasectomy (Table I). Metastasectomy patients were significantly younger (62 vs. 64 years, $p<0.001)$, more frequently harbored lower T-stage tumors $(p=0.001), \mathrm{N} 0 / \mathrm{NX}$ stage $(p=0.004)$ and clear-cell histology $(p=0.006)$. Metastasectomy utilization rate was not significantly different over the study period (from 16.3 to $13.0 \%$, $\mathrm{EAPC}=-2.3 \%, p=0.2$ ).

In multivariable logistic regression models, independent predictors of lower metastasectomy rate were older age [odds ratio $(\mathrm{OR})=0.9,95 \%$ confidence interval $(\mathrm{CI})=0.8-0.9$, $p<0.001$ ], T3 (OR 0.5, 95\% CI=1.4-5.8, $p<0.001)$ and T4 stages $(\mathrm{OR}=0.6,95 \% \mathrm{CI}=0.4-0.9, p=0.01)$ and $\mathrm{N} 1$ stage $(\mathrm{OR}=0.7,95 \% \mathrm{CI}=0.6-0.9, p=0.02)$.

Before 1: 4 PSM, median overall survival for those who underwent metastasectomy versus those who did not was 11 (95\% CI=10-13) compared with 9 (95\% CI=8-9) months $(p=0.0008)$, respectively (Figure 1A). In MCR models predicting OM, metastasectomy was associated with lower OM [hazard ratio $(\mathrm{HR})=0.83,95 \% \mathrm{CI}=0.73-0.94, p=0.002]$.
After 1: 4 PSM, all covariates were balanced between metastasectomy $(n=347)$ and no-metastasectomy $(n=1,713)$ patients. Median overall survival with PSM was $11(95 \%$ $\mathrm{CI}=10-13)$ versus 9 (95\% $\mathrm{CI}=9-10)$ months $(p=0.0005)$, respectively (Figure 1B). In MCR models predicting OM, metastasectomy was still significantly associated with lower $\mathrm{OM}(\mathrm{HR}=0.80,95 \% \mathrm{CI}=0.71-0.91, p=0.001)$.

Within the NIS database (2006-2015), 351 patients treated with metastasectomy were identified. Only 31 patients were treated with stereotactic radiosurgery metastasectomy (Table II). Metastasectomy patients had a median age of 64 years [interquartile range $(\mathrm{IQR})=56-71]$, were mainly treated at teaching hospitals $(62.4 \%)$ and in either medium- $(62.4 \%)$ or high-volume centers $(37.6 \%)$. The median length of stay was 7 days (IQR=4-11 days). Overall, complications occurred in $193(55.5 \%)$ of the patients. The most frequent complication types were pulmonary $(21.9 \%)$ and transfusions $(15.7 \%)$. The in-hospital mortality rate was $4.6 \%$ (16 patients).

The most common site of metastasis was the lung $(82.3 \%)$, followed by bone $(24.5 \%)$, liver $(15.9 \%)$, the brain (14.2\%), lymph nodes $(13.9 \%)$ and the adrenal glands (8.8\%). Metastasectomy was predominantly performed for lung $(79.2 \%)$, followed by bone $(3.7 \%)$, liver $(3.4 \%)$, lymph nodes $(2.0 \%)$, adrenal $(1.7 \%)$ and brain $(1.1 \%)$ metastases. At univariable logistic regression analyses predicting overall complications, none of the examined variables reached statistical significance (all $p>0.05$ ).

\section{Discussion}

Previous retrospective data suggested that select patients with favorable or intermediate risk (10) may benefit from metastasectomy after cytoreductive nephrectomy and may achieve better survival outcomes $(3,4,11)$. However, to the best of our knowledge, no previous studies specifically 
Table II. Descriptive characteristics of 351 patients treated with metastasectomy for metastatic renal cell carcinoma, identified within the National In-patient Sample (2006-2015).

\begin{tabular}{|c|c|}
\hline Variable & Value \\
\hline \multicolumn{2}{|l|}{ Age, years } \\
\hline Median (IQR) & $64(56-71)$ \\
\hline \multicolumn{2}{|c|}{ Year of treatment, n (\%) } \\
\hline 2006-2010 & $183(52.1)$ \\
\hline 2011-2015 & $168(47.9)$ \\
\hline \multicolumn{2}{|l|}{ Gender, n (\%) } \\
\hline Male & $222(63.2)$ \\
\hline \multicolumn{2}{|l|}{ Ethnicity, n (\%) } \\
\hline Caucasian & $223(63.5)$ \\
\hline African American & $28(8.0)$ \\
\hline Other/unknown & $100(28.5)$ \\
\hline \multicolumn{2}{|l|}{$\mathrm{CCI}, \mathrm{n}(\%)$} \\
\hline 0 & $219(62.4)$ \\
\hline 1 & $79(22.5)$ \\
\hline$\geq 2$ & $53(15.1)$ \\
\hline \multicolumn{2}{|l|}{ Insurance, n (\%) } \\
\hline Medicare & $155(44.2)$ \\
\hline Medicaid & $43(12.3)$ \\
\hline Private & $128(36.5)$ \\
\hline Other & $25(7.1)$ \\
\hline \multicolumn{2}{|l|}{ Region, n (\%) } \\
\hline Midwest & $84(23.9)$ \\
\hline Northeast & $61(17.4)$ \\
\hline South & $137(39.0)$ \\
\hline West & $69(19.7)$ \\
\hline \multicolumn{2}{|c|}{ Income quartile, $\mathrm{n}(\%)^{\#}$} \\
\hline First & $95(27.1)$ \\
\hline Second & $90(25.6)$ \\
\hline Third & $86(24.5)$ \\
\hline Fourth & $70(22.8)$ \\
\hline \multicolumn{2}{|c|}{ Annual hospital volume, $\mathrm{n}(\%)^{*}$} \\
\hline Low & $0(0)$ \\
\hline Medium & $219(62.4)$ \\
\hline High & $132(37.6)$ \\
\hline \multicolumn{2}{|c|}{ Teaching status, n (\%) } \\
\hline Teaching & $219(62.4)$ \\
\hline Non-teaching & $132(37.6)$ \\
\hline \multicolumn{2}{|l|}{ Complication, $\mathrm{n}(\%)$} \\
\hline Yes & $193(55.0)$ \\
\hline \multicolumn{2}{|l|}{ Transfusion, n (\%) } \\
\hline Yes & $55(15.7)$ \\
\hline \multicolumn{2}{|l|}{ Length of stay, days } \\
\hline Median (IQR) & $7(4-11)$ \\
\hline \multicolumn{2}{|c|}{ In hospital mortality, n (\%) } \\
\hline Yes & $16(4.6)$ \\
\hline
\end{tabular}

IQR: Interquartile range; CCI: Charlson Comorbidity Index. "Defined according to ZIPINC variable provided by the NIS database. * Defined by calculating the total number of procedures in the sample for each unique hospital identifier per year.

investigated the potential survival benefit of metastasectomy in patients with mRCC treated exclusively with targeted therapy.

Firstly, the rate of metastasectomy for patients with mRCC treated exclusively with targeted therapy was $12.0 \%$
(437 patients). This rate is slightly inferior to those previously reported for patients previously treated with cytoreductive nephrectomy $(4,11)$. Nonetheless, the lower rates reported in the current study are expected in a noncytoreductive nephrectomy-treated cohort and are in agreement with recommendations for use of metastasectomy in highly select patients $(1,2)$.

Secondly, metastasectomy patients were younger and more frequently harbored tumor with lower TNM stage. Additionally, higher stage and nodal involvement represented independent predictors of lower metastasectomy use. These findings also suggest that metastasectomy in patients with mRCC treated exclusively with targeted therapy is generally reserved for those with more favorable tumor phenotype.

Thirdly, metastasectomy was associated with lower OM both before (HR=0.83, $p=0.002)$ and after 1: 4 PSM (HR=0.80, $p=0.001$ ). However, these highly statistically significant relative benefit ratios for metastasectomy were based on a short absolute benefit of only 2 months (median overall survival 11 versus 9 months). These median overall survival values indicate that our cohort of patients with mRCC very closely approximated the poor-risk group (12). Therefore, metastasectomy use should be critically reviewed in a multidisciplinary context owing to the short absolute survival benefit that we identified.

Fourthly, only one study previously investigated metastasectomy within the NIS (13). Conversely from Meyer et al. (14), we only excluded patients simultaneously treated with cytoreductive nephrectomy. Even though the vast majority of patients were treated at teaching hospitals, the overall complication rate $(55.0 \%)$ and in-hospital mortality $(4.6 \%)$ after metastasectomy were non-negligible. These rates were higher than those previously reported form populationbased database (14) and centers of excellence $(13,15)$.

Despite the strengths of this study, important limitations need to be acknowledged, such as the retrospective nature, as well as the lack of information about laboratory variables, performance status, exact tumor burden, dose and duration of targeted therapy and immunotherapy.

\section{Conflicts of Interest}

All the Authors declare they have no potential conflict of interest to disclose in regard to this study.

\section{Authors' Contributions}

Conception and design: Palumbo, Karakiewicz. Acquisition of data: Palumbo, Pecoraro, Knipper, Rosiello, Tian. Analysis and interpretation of data: Palumbo, Karakiewicz, Pecoraro, Knipper, Rosiello, Tian. Drafting of the article: Palumbo, Pecoraro, Karakiewicz. Statistical analysis: Palumbo, Tian. Critical revision of the article for important intellectual content: Shariat, Simeone, Briganti, Saad, Berruti, Antonelli. Supervision: Karakiewicz. Obtaining funding/administrative support: None. 


\section{Acknowledgements}

None.

\section{References}

1 Ljungberg B, Albiges L, Bensalah K, Bex A, Giles RH, Hora M, Kuczyk MA, Lam T, Marconi L, Merseburger AS, Powles T, Staehler M and Volpe A: European Association of Urology Guidelines. 2018 Edition. Available from: https: //uroweb.org/ guideline/renal-cell-carcinoma/ (Last accessed: June 14, 2019)

2 Motzer RJ, Jonasch E, Fishman M, Gallagher TH, McDonald A, Michaelson MD and Agarwal N: National Comprehensive Cancer Network (NCCN) Clinical Practice Guidelines in Oncology. Kidney Cancer version 3.2018. Available at: http://oncolife.com.ua/doc/nccn/Kidney_Cancer.pdf (Last accessed June 20, 2019)

3 Karam JA, Rini BI, Varella L, Garcia JA, Dreicer R, Choueiri TK, Jonasch E, Matin SF, Campbell SC, Wood CG and Tannir NM: Metastasectomy after targeted therapy in patients with advanced renal cell carcinoma. J Urol 185: 439-444, 2011. PMID: 21167518. DOI: 10.1016/j.juro.2010.09.086

4 Sun M, Meyer CP, Karam JA, de Velasco G, Chang SL, Pal SK, Trinh Q-D and Choueiri TK: Predictors, utilization patterns, and overall survival of patients undergoing metastasectomy for metastatic renal cell carcinoma in the era of targeted therapy. Eur J Surg Oncol 44: 1439-1445, 2018. PMID: 29935840. DOI: 10.1016/j.ejso.2018.05.026

5 About the SEER Program. SEER. Available at: https:// seer.cancer.gov/about/overview.html (Last accessed March 21, 2019)

6 ICD-O manual. Available at: https: //codes.iarc.fr/ (Last accessed June 14, 2019)

7 TNM Classification of Malignant Tumors. UICC International Union Against Cancer. Seventh Edition. Brierley JD, Gospodariwicz M and Wittekind C (eds.). Wiley-Blackwell, 2009.

8 HCUP-US NIS Overview. Available at: https://www.hcupus.ahrq.gov/nisoverview.jsp (Last accessed March 21, 2019).

9 Bartlett EK, Simmons KD, Wachtel H, Roses RE, Fraker DL, Kelz RR and Karakousis GC: The rise in metastasectomy across cancer types over the past decade: Metastasectomy trends. Cancer 121: 747-757, 2015. PMID: 25377689. DOI: 10.1002/ cncr.29134
10 Zaid HB, Parker WP, Safdar NS, Gershman B, Erwin PJ, Murad MH, Boorjian SA, Costello BA, Thompson RH and Leibovich BC: Outcomes following complete surgical metastasectomy for patients with metastatic renal cell carcinoma: A systematic review and meta-analysis. J Urol 197: 44-49, 2017. PMID: 27473875. DOI: $10.1016 /$ j.juro.2016.07.079

11 Dabestani S, Thorstenson A, Lindblad P, Harmenberg U, Ljungberg B and Lundstam S: Renal cell carcinoma recurrences and metastases in primary non-metastatic patients: A populationbased study. World J Urol 34: 1081-1086, 2016. PMID: 26847337. DOI: 10.1007/s00345-016-1773-y

12 Motzer RJ, Bacik J, Murphy BA, Russo P and Mazumdar M: Interferon-alfa as a comparative treatment for clinical trials of new therapies against advanced renal cell carcinoma. J Clin Oncol 20: 289-296, 2002. PMID: 11773181. DOI: 10.1200/JCO. 2002.20. 1.289

13 Kudelin N, Bölükbas $\mathrm{S}$, Eberlein $\mathrm{M}$ and Schirren $\mathrm{J}$ : Metastasectomy with standardized lymph node dissection for metastatic renal cell carcinoma: An 11-year single-center experience. Ann Thorac Surg 96: 265-271, 2013. PMID: 23731615. DOI: 10.1016/j.athoracsur.2013.04.047

14 Meyer CP, Sun M, Karam JA, Leow JJ, de Velasco G, Pal SK, Chang SL, Trinh Q-D and Choueiri TK: Complications after metastasectomy for renal cell carcinoma - A population-based assessment. Eur Urol 72: 171-174, 2017. PMID: 28359734. DOI: 10.1016/j.eururo.2017.03.005

15 Hatzaras I, Gleisner AL, Pulitano C, Sandroussi C, Hirose K, Hyder O, Wolfgang CL, Aldrighetti L, Crawford M, Choti MA and Pawlik TM: A multi-institution analysis of outcomes of liverdirected surgery for metastatic renal cell cancer. HPB 14: 532-538, 2012. PMID: 22762401. DOI: 10.1111/j.1477-2574.2012.00495.x
Received May 20, 2019

Revised June 14, 2019

Accepted June 20, 2019 